\title{
The relationship between the motor skills level and the severity of autism disorder in children with autism
}

\author{
Ali Akbar Barrodi sedehi ${ }^{1 \mathrm{ABCDE}}$, Abdollah Ghasemi ${ }^{2 \mathrm{ABCD}}$, Ali Kashi ${ }^{3 \mathrm{ABCD}}$, Elham Azimzadeh ${ }^{4 \mathrm{ABCD}}$ \\ 1,2Department of Physical Education, Science and Research Branch, Islamic Azad University, Tehran, Iran \\ ${ }^{3}$ Sport Science Research Institute of Iran (SSRI), Tehran, Iran \\ ${ }^{4}$ Faculty of Sport Sciences, Shahid Beheshti University, Tehran, Iran
}

Authors' Contribution: A - Study design; B - Data collection; C - Statistical analysis; D - Manuscript Preparation; E - Funds Collection

\begin{abstract}
Purpose:

This study aimed to determine the relationship between the level of fine and gross motor skills and motor proficiency with the severity of autism disorder in children with autism.

Material: 68 children with autism, ranged from 3-16 years old, were selected. Motor Assessment Battery for Children-2 (MABC-2) was used to assess fine and gross motor skills and motor proficiency. Gilliam Autism Rating Scale-2 (GARS-2) test was also used for assessing the severity of autism disorder in the participants.

Results: The obtained results from the Pearson correlation test showed that there was a significant and negative relationship between sub-scales of GARS- 2 and MABC- 2 tests $(P<0.05)$. It means that decreasing the level of motor skills increases the autism severity. The results of the regression test also showed that only the total score of motor proficiency among microscales of the MABC-2 test could predict the stereotypes, social skills, communication skills, and autism severity $(\mathrm{P}<0.05)$.

Conclusions: $\quad$ The results of the current study indicated the pivotal role of motor skills growth in determining the level of autism disorder. It also emphasized on embedding motor interventions in rehabilitation programs of such people.

Keywords:

autism, motor skills, fine motor skills, gross motor skills
\end{abstract}

\section{Introduction}

Autism spectrum disorder (ASD) is one of the developmental disorders with symptoms of deficit in social communication and interaction with others and stereotypes in the person [1]. Although the main feature of this disorder includes the deficits of social relationships, there are many pieces of evidence, indicating that children with autism have different levels of motor skills deficits as well which cannot be described by mere neurocognitive mechanisms [2]. Motor deficits, mostly seen in people with autism, include delay in fine and gross skills development [2-4], the deficit in walking such as differences in joint angles and forces on the ground [5], postural instability because of the problem in sensory processing [6] and the problems of coordinating the motor organs in planning and implementing the movement [7]. Such motor deficits are even observable in early birth ages before age one for delay in fundamental motor skills [8]. Because the etiology of autism spectrum disorder is not clear yet, the role of motor skills in this disorder is not well known.

The complementary development theories assume about the normal children that the growth of all person's aspects depends on the interaction between different growth ranges. For example, the embodiment hypothesis of the dynamic system theory argues that growth aspects never grow alone [9]. Yet, growth changes form as the result of interaction between the environment and motorperceptional experiences. Therefore, a child's motor experiences can affect the growth of other aspects of him such as cognitive, social, and relational. The supporting

\footnotetext{
(c) Ali Akbar Barrodi sedehi, Abdollah Ghasemi, Ali Kashi, Elham Azimzadeh, 2021
}

doi:10.15561/26649837.2021.0108 evidence of this theory can be seen in normal people and even those with other growth disorders such as Cerebral Palsy [11]. For example, normal children in kindergarten, having higher motor skills, participate in group games, and have less social problems with other kids [10]. In children with Cerebral Palsy, the level of motor growth predicts their social performance [11].

The studies about motor skills in people with autism are not clear. It is shown that gross motor skills growth has a relationship with disorder symptoms in children [12] and adolescents [13] while others did not find any relationship between these fields in 4-12.5-year-old people [14]. The contrast in findings might be due to differences in the methodology of previous studies. No significant difference was seen in a study, conducted with a high volume of samples while many children showed a high level of motor skills due to the ceiling and floor effects in the gross motor skill assessment tool [14]. Different findings have been reported in the case of the relationship between gross motor skills and social skills [14-16]. Most of the studies, which have shown a low relationship between social skills and motor growth, have been conducted in the societies, whose participants had been in childhood. Whereas the wider age range showed a better perception of the rate and form of relationship between motor skills and social skills in people with autism. Pusponegoro et al [15] reported lower motor skills in 1,2,3-year-old children with autism in comparison with normal ones though they only assessed the relationship between motor and social skills in the group.

The current study aimed to determine the relationship between the level of fine, gross motor skills, and motor proficiency with related components to autism disorder in 
children of 3 to 16 years old. The reason for choosing this range of age was the comprehensiveness of the studied sample and better determination of the relationship between the variables in the age range and growth period. It was also tried in this study to investigate the predictability of autism disorder level based on the level of motor skills.

\section{Material and Methods}

Participants

In order to conduct this study, 68 children with autism in the age range of 3 to 16 years old (mean=8.27, standard deviation $=3.20$ ) were chosen and investigated through referring to educational and rehabilitation centers for children with autism in Mashhad. The inclusion criteria of the study were confirmed autism disorder by the psychiatrist, no simultaneous disorders and diseases such as hyperactivity, mental retardation, structural, musculoskeletal deficits, no cardiovascular diseases, and epilepsy. After being briefed about the study, all parents signed the conscious consent forms.

\section{Instruments}

Gilliam Autism Rating Scale-2 (GARS-2)

This questionnaire is one of the most common tools for assessing ASD with 42 items, which assesses three fields of stereotypes, social skills, and communicational skills in a person. The score of each item ranges from 0 to 2 so that score 0 is rarely, 1 sometimes and 2 most of the time. The highest score in each sub-scale is 42 and the lowest one zero. Higher scores indicate more severity. In the end, participants were divided into three levels of autism with a probability of very low, average, and high [17]. The test can be used for the ages 3 to 22 and shall be completed by a person who is aware enough about the participant such as parents or teachers. The main version of this test has been tested and standardized on 1092 American and Canadian children, adolescents, and adults. According to the different studies, the reliability of the test, calculated by Cronbach's alpha, has been obtained 0.9 for stereotypes, 0.89 for communicating, 0.93 for social interaction, and 0.96 for autism symptoms. The Persian version of this test was validated by Ahmadi et al. (2011) and showed that Cronbach's alpha in stereotypes is equal to $0.74,0.92$ in communicating, 0.73 in social interactions, and 0.89 as total score [18].

Movement Assessment Battery for Children-Second Edition (MABC-2)

MABC-2 is one of the most used tests of assessing and diagnosing motor disorders in children. It proposes three components of fine, gross motor skills and total score of motor proficiency of the person [19]. It has a specific norm and is used in the age range from 3 to 17 . The test is the result of two decades of studies by Henderson et al. [1] and includes three age groups of 3-6 years old, 7-10 years old, and 11-17 years old. The test includes a checklist and descriptive instruction for identifying children with motor coordination disorder. Implementing the test includes a series of fine and gross motor tasks. The tasks are grouped in three parts; 1- manual dexterity skill (including the skills of inserting pins, threading and drawing the maze), 2- targeting and throwing skill (including the activities of catching and throwing the ball and bin sack) and 3balancing skill (including one-food standing, walking on the heel of the toe and hopscotch). The total time of the test is around 2- to 40 minutes [19]. Akbaripur et al. [20] have validated it in Iran. On this basis, Cronbach's alpha was obtained as 0.843 .

\section{The method of implementation}

After checking with the centers and participants' parents, the selected children were evaluated by motor behavior experts using the MABC-2 test one by one. The test was conducted in a calm condition with the cooperation of children's trainers in their educational place because the new conditions affect participants' performance. The children's parents and trainers also responded to the GARS-2 questionnaire. The raw scores of both tests were converted to standard scores and related coefficients by the experts and using related norms and instructions and they were utilized in statistical analysis.

Statistical Analysis

To determine the relationship between the variables, the Pearson correlation test was used. to determine the predictability of participant's autism rate scores from their motor skill scores, linear regression was also used. All statistical tests were conducted by SPSS-23 software at a statistical level of $\alpha=0.05$.

\section{Results}

Table 1 shows the study participants' cognitive demography.

The obtained results of the current study showed that $4.3 \%$ of the participants were in the green zone, $2.9 \%$ in the yellow zone, and $92.9 \%$ in the red zone in terms of motor skills growth. The results indicated the high prevalence of motor deficits in such people. in terms of the severity of the disorder, given the results of Garza test2 , it was also seen that $2.9 \%$ of participants are likely to have mild autism, $21.4 \%$ average autism, and $75.7 \%$ high autism.

The obtained results from the Pearson correlation test (table 2) indicate the significant relationship between microscales of GARS-2 test and fine skills $(\mathrm{P}<0.05)$, gross skills $(\mathrm{P}<0.05)$, and total score of motor skills of children with autism $(\mathrm{P}<0.05)$. The rate of such relationships can be seen in figure 1 .

Multilinear regression was used to determine the possibility of predicting autism coefficient from motor skills, the results of which can be seen in table 3 .

As indicated in table 3, the regression model has been signified. Index $\mathrm{R}^{2}$ adj also shows that microscales of fine, gross skills and motor proficiency can predict autism level for $37 \%$. It was also observed that among the variables of fine, gross motor skills and motor proficiency, only the motor proficiency can predict autism level in the participants.

The obtained results from table 4 show that motor proficiency with a regression weight of -0.85 can predict autism level. The negative amount of this coefficient 
Table 1. Participants' demography

\begin{tabular}{lllll}
\hline Variable & Minimum & Maximum & Standard deviation & Mean \\
\hline Age & 3.10 & 16.80 & 3.20 & 8.27 \\
\hline Stereotypes & 4 & 17 & 2.88 & 8.77 \\
GARS I & 4 & 3.52 & 9.70 \\
\hline Communicational skills & 19 & & 8.77 \\
GARS II & 4 & 16 & 2.72 & 96.61 \\
\hline Social skills & & & 17.65 & 3.41 \\
GARS III & 66 & 151 & 1.96 & 6.67 \\
\hline Autism level & 1 & 9 & 4.86 & 28.72 \\
\hline Fine skills & 2 & 22 & 15.18 & \\
\hline Gross skills & 6 & 66.5 & & \\
\hline Motor proficiency & & & & \\
\hline
\end{tabular}

Table 2. The results of the Pearson correlation test

\begin{tabular}{lllllll}
\hline \multirow{2}{*}{ Microscale } & \multicolumn{2}{c}{ Fine skill } & \multicolumn{2}{c}{ Gross skill } & \multicolumn{2}{c}{ Motor proficiency } \\
\cline { 2 - 7 } & $\mathbf{r}$ & Sig & $\mathbf{r}$ & Sig & $\mathbf{r}$ & Sig \\
\hline Stereotypes & -0.372 & 0.0001 & -0.570 & 0.0001 & -0.613 & 0.0001 \\
Communicational skills & -0.413 & 0.0001 & -0.460 & 0.0001 & -0.530 & 0.0001 \\
Social interaction & -0.436 & 0.0001 & -0.557 & 0.0001 & -0.610 & 0.0001 \\
Autism coefficient & -0.492 & 0.0001 & -0.519 & 0.0001 & -0.629 & 0.0001 \\
\hline
\end{tabular}

Table 3. Regression analysis of predicting autism level from motor skills

\begin{tabular}{lllllllll}
\hline Model & $\begin{array}{l}\text { Total } \\
\text { squares }\end{array}$ & $\begin{array}{l}\text { Degrees of } \\
\text { freedom }\end{array}$ & Mean squares & $\mathbf{F}$ & $\mathbf{R}$ & $\mathbf{R}^{2}$ & $\mathbf{R}_{\text {adj }}$ & $\mathbf{S i g}^{2}$ \\
\hline Regression & 8631.04 & 3 & 2877.01 & 14.75 & 0.634 & 0.402 & 0.374 & 0.001 \\
The remained & 12865.5 & 66 & 194.93 & & & & & \\
Total & 21496.5 & 69 & & & & \\
\hline
\end{tabular}

Table 4. Standard and non-standard coefficients and inserted t-statistic in the regression model

\begin{tabular}{lllll}
\hline \multirow{2}{*}{ Predictor variable } & \multicolumn{2}{l}{ Regression coefficients } & T-statistic & Sig \\
\cline { 2 - 3 } & B & Beta & & 0.001 \\
\hline Fixed amount & 118.26 & & 31.70 & 0.707 \\
Fine skill & 0.651 & 0.073 & 0.377 & 0.443 \\
Gross skill & 0.715 & 0.197 & 0.772 & 0.017 \\
\hline Motor proficiency & -0.997 & -0.858 & -2.44 & \\
\hline
\end{tabular}



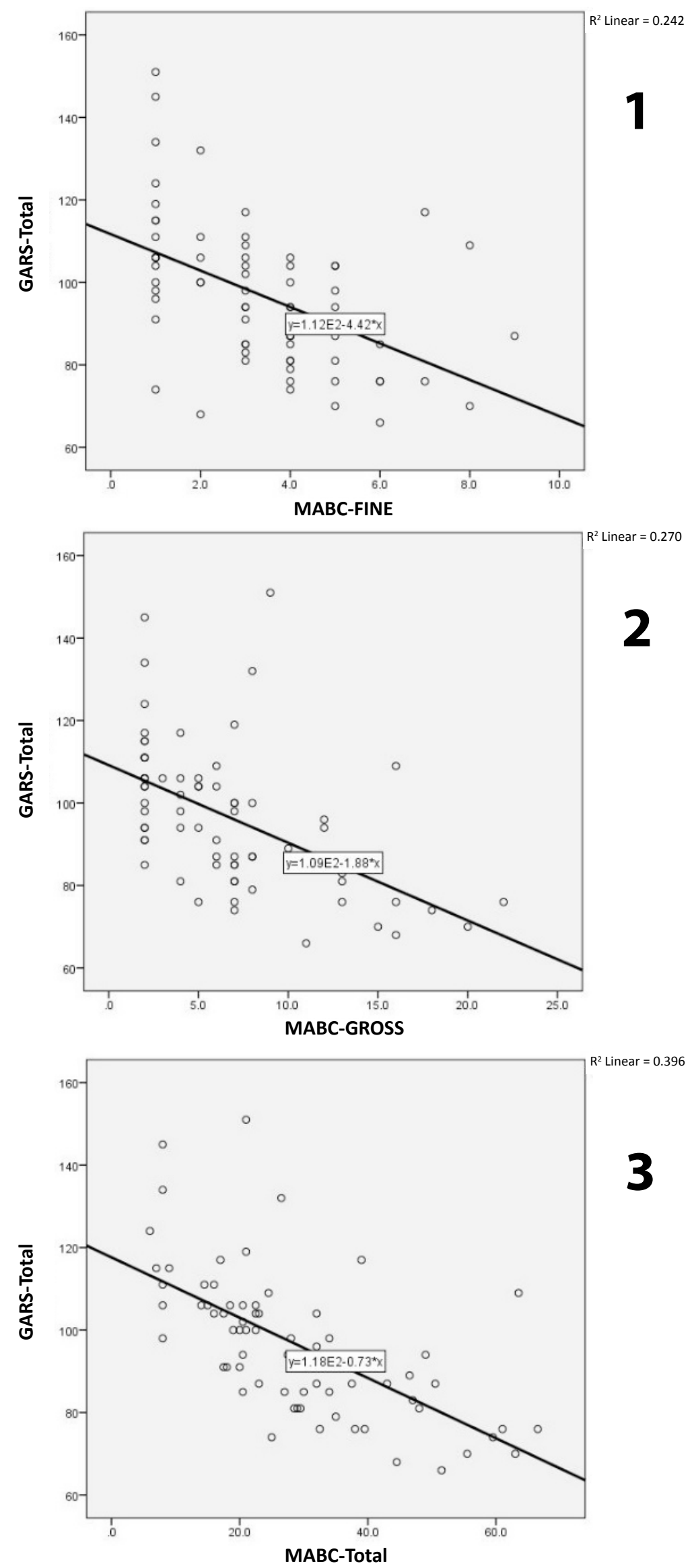

Figure 1. The fitness of correlation in fine skill and the severity of autism disorder (1), gross skills and the severity of the disorder (2) and motor proficiency and the severity of the disorder (3) 
indicates that increasing the level of motor proficiency decreases the autism level of the participants.

\section{Discussion}

The results of the current study are consistent with the previous ones, indicating a significant relationship between the level of motor skills and social skills [15, 21]. Pozonger and [15] showed that children with autism who had lower motor skills showed lower social skills as well. Modi et al. [21] showed that gross motor skills have a relationship with social interaction though they did not observe the quality of communicational social relations. Hirata et al. [16] reported an average but not a significant correlation between motor skill and social performance of 7-16-year-old children with autism. Whereas, the relationship has been signified in the current study which can be because of the manner of early intervention of parents and concentrating on early treatments on their children.

The previous findings of the relationship between social skills and motor deficits are also consistent with the findings of the current study. The important point of these findings is the relationship between all three indicators of fine, gross skills and motor proficiency in children with autism. It has been also shown that weak performance in the tasks, requiring visual feedbacks such as receiving the ball or static balance, has been different in children with autism from those children with hyperactivity and attention deficit [3]. Moreover, people with autism have different visual information in comparison with normal people [6] which can be a reason for their weaker performance in such tasks. The existing tasks in microscale of manipulating the things and the balance of the MABC-2 test include knocking, grabbing, and standing on one foot. As a result, in addition to problems of visual processors, the weaker performance in such fields is likely justified by other motor components such as balancing or motor coordination.

The relationship between gross motor skills and the severity of disorder was also consistent with previous studies, showing that children with severe autism are weak in gross motor skills [12]. Interestingly, some studies have found out that the total level of gross motor skills is not related to the severity of autism and the deficit in some specific skills such as controlling the thing [22] and postural stability [13] had a relationship with autism. In the investigation of the relationship between combinational motor skills and social performance with autism severity, no significant relationship was seen [14]. One of the probable reasons for the difference between their study with the current one can be the difference in age range and tools of assessing motor skills or the severity of autism disorder.

It was also shown in the current study that the motor proficiency level of children with autism may predict the severity of the disorder in them. It might be because when the child can keep his postural stability balanced, he has to involve high physical and mental resources in processing his postural appropriate status so less capacity will remain for other resources such as social participant. Ajzenman et al. [22] observed an improvement in controlling the posture and following that in social communication after horse treatment intervention. They concluded that improving motor-perceptional abilities may create a tendency in the child for making social relationships [22]. Similarly, the ability to throw or hit a ball requires visual feedback and perceiving and predicting others' social responses. It is generally assumed that ball skills, given their nature, have a relationship with social performances [23].

The idea of the relationship between motor abilities and other growth aspects may be highly used in therapeutic interventions. It is suggested that motor interventions can be beyond the improvement of mere motor skills. Improving motor skills in children with autism may improve social skills and their other capabilities. The International Classification of Function Model encourages the disability of providers for a comprehensive image of disability, involving numerous effective factors on the total participation of the person [24]. While it cannot be certainly said that weakness in balancing or ball skills is the reason for social skills deficit in people with autism, the interventions, concentrating on the improvement of such abilities, might improve social skills in the people of this society. Previous interventions such as horse therapy, water therapy, or the motor skill-based approaches have shown some benefits for socializing [23, 24]. Although further studies are needed, the findings of the current study suggest that motor skills have a relationship with the main symptoms of autism and shall be considered in the interventions. Moreover, the current study suggests that the experts of different fields shall consider the creation of motor status for growing other related growth fields with autism. Similar to most children with growth disorders, the complicated nature of autism requires a team approach, in which all team members cooperate to design an appropriate program.

\section{Conclusion}

The current study showed that there is a relationship between motor skills and ASD symptoms. The participants' motor proficiency scores could predict their autism level. The motor ability of people also changed given the severity of the disorder. The later studies shall investigate the effect of motor interventions on the improvement of related capabilities to autism disorder.

\section{Conflict of interest}

Authors declare no conflict of interest. 


\section{References}

1. American Psychiatric Association Diagnostic and Statistical Manual of Mental Disorders (DSM-IV). SpringerReference, Berlin/Heidelberg: $\quad$ Springer-Verlag; 2011. https://doi.org/10.1007/SpringerReference_179660

2. McPhillips M, Finlay J, Bejerot S, Hanley M. Motor deficits in children with autism spectrum disorder: A crosssyndrome study. Autism Research. 2014;7(6):664-76. https://doi.org/10.1002/aur.1408

3. Ament K, Mejia A, Buhlman R, Erklin S, Caffo B, Mostofsky $\mathrm{S}$, et al. Evidence for specificity of motor impairments in catching and balance in children with autism. Journal of Autism and Developmental Disorders. 2015;45(3):742-51. https://doi.org/10.1007/s10803-014-2229-0

4. Lane A, Harpster K, Heathcock J. Motor characteristics of young children referred for possible autism spectrum disorder. Pediatric Physical Therapy. 2012;24(1):21-9. https://doi.org/10.1097/pep.0b013e31823e071a

5. DufekJS, Eggleston JD, Harry JR, HickmanRA.Acomparative evaluation of gait between children with autism and typically developing matched controls. Medical Sciences. 2017;5(1):1. https://doi.org/10.3390/medsci5010001

6. Morris SL, Foster CJ, Parsons R, Falkmer M, Falkmer T, Rosalie SM. Differences in the use of vision and proprioception for postural control in autism spectrum disorder. Neuroscience. 2015;307:273-80. https://doi.org/10.1016/j.neuroscience.2015.08.040

7. Fournier KA, Hass CJ, Naik SK, Lodha N, Cauraugh $\mathrm{JH}$. Motor coordination in autism spectrum disorders: a synthesis and meta-analysis. Journal of Autism and Developmental Disorders. 2010;40(10):1227-40. https://doi.org/10.1007/s10803-010-0981-3

8. Arabameri E, Sotoodeh MS. Early developmental delay in children with autism: a study from a developing country. Infant Behavior and Development. 2015;39:118-23. https://doi.org/10.1016/j.infbeh.2015.02.017

9. Thelen E. Dynamic systems theory and the complexity of change. Psychoanalytic Dialogues. 2005;15(2):255-83. https://doi.org/10.1080/10481881509348831

10. Whittingham K, Fahey M, RawickiB, Boyd R. The relationship between motor abilities and early social development in a preschool cohort of children with cerebral palsy. Research in Developmental Disabilities. 2010;31(6):1346-51. https://doi.org/10.1016/j.ridd.2010.07.006

11.Bar-Haim Y, Bart O. Motor function and social participation in kindergarten children. Social Development. 2006;15(2):296-310. https://doi.org/10.1111/j.1467-9507.2006.00342.x

12.MacDonald M, Lord C, Ulrich DA. Motor skills and calibrated autismseverityinyoung childrenwithautismspectrumdisorder. Adapted Physical activity Quarterly. 2014;31(2):95-105. https://doi.org/10.1123/apaq.2013-0068

13. Travers BG, Powell PS, Klinger LG, Klinger MR. Motor difficulties in autism spectrum disorder: linking symptom severity and postural stability. Journal of Autism and Developmental Disorders. 2013;43(7):1568-83. https://doi.org/10.1007/s10803-012-1702-x

14.Colombo-DougovitoAM, Reeve RE. Exploring the interaction of motor and social skills with autism severity using the SFARI dataset. Perceptual and Motor Skills. 2017;124(2):413-24. https://doi.org/10.1177/0031512516689198

15.Pusponegoro HD, Efar P, Soebadi A, Firmansyah A, Chen H-J, Hung K-L. Gross motor profile and its association with socialization skills in children with autism spectrum disorders. Pediatrics \& Neonatology. 2016;57(6):501-7. https://doi.org/10.1016/j.pedneo.2016.02.004

16. Hirata S, Okuzumi H, Kitajima Y, Hosobuchi T, Nakai A, Kokubun M. Relationship between motor skill and social impairment in children with autism spectrum disorders. International Journal of Developmental Disabilities. 2014;60(4):251-6. https://doi.org/10.1179/2047387713y.0000000033

17.Pandolfi V, Magyar CI, Dill CA. Constructs assessed by the GARS-2: factor analysis of data from the standardization sample. Journal of Autism and Developmental Disorders. 2010;40(9):1118-30. https://doi.org/10.1007/s10803-010-0967-1

18.Ahmadi SJ, Safari T, Hematian M, Khalili Z. Investiagting the Psychometric Indicators of Autism Diagnostic Test (GARS) (Isfahan Autism Children Education and Rehabilitation Center). Cognitive and Behavioral Research. 2011;1(1):87104.

19.Brown T, Lalor A. The movement assessment battery for children-second edition (MABC-2): a review and critique. Physical \& Occupational Therapy in Pediatrics. 2009;29(1):86-103. https://doi.org/10.1080/01942630802574908

20.Mody M, Shui A, Nowinski L, Golas S, Ferrone C, O'Rourke J, et al. Communication deficits and the motor system: exploring patterns of associations in autism spectrum disorder (ASD). Journal of Autism and Developmental Disorders. 2017;47(1):155-62. https://doi.org/10.1007/s10803-016-2934-y

21.Ajzenman HF, Standeven JW, Shurtleff TL. Effect of hippotherapy on motor control, adaptive behaviors, and participation in children with autism spectrum disorder: a pilot study. American Journal of Occupational Therapy. 2013;67(6):653-63. https://doi.org/10.5014/ajot.2013.008383

22.Holloway JM, Long TM, Biasini F. Relationships Between Gross Motor Skills and Social Function in Young Boys With AutismSpectrumDisorder.PediatricPhysicalTherapy,2018:1. https://doi.org/10.1097/PEP.0000000000000505

23.Ennis E. The effects of a physical therapy-directed aquatic program on children with autism. Journal of Aquatic Physical Therapy. 2011;19(1):4-10.

24.Organization WH. International Classification of Functioning, Disability, and Health: Children \& Youth Version: ICF-CY. World Health Organization; 2007. 


\section{Information about the authors:}

Ali Akbar Barrodi sedehi; Ph.D Student; https://orcid.org/0000-0002-2464-9264; Barrodi_akbar@yahoo.com; Department of Physical Education, Science and Research Branch, Islamic Azad University; Tehran, Iran.

Abdollah Ghasemi; (Corresponding Author); Assistant Professor; https://orcid.org/0000-0001-7113-6894; ghasemi_abdolla@ yahoo.com; Department of Physical Education, Science and Research Branch, Islamic Azad University; Tehran, Iran.

Ali Kashi; Assistant Professor; https://orcid.org/0000-0003-1125-9125; ssrc.kashi@gmail.com; Sport Science Research Institute of Iran (SSRI); Tehran, Iran.

Elham Azimzadeh; Assistant Professor; https://orcid.org/0000-0001-9838-0117; e_azimzadeh@sbu.ac.ir; Faculty of Sport Sciences, Shahid Beheshti University; Tehran, Iran.

Cite this article as:

Barrodi sedehi AA, Ghasemi A, Kashi A, Azimzadeh E. The relationship between the motor skills level and the severity of autism disorder in children with autism. Pedagogy of Physical Culture and Sports, 2021;25(1):59-65. https://doi.org/10.15561/26649837.2021.0108

This is an Open Access article distributed under the terms of the Creative Commons Attribution License, which permits unrestricted use, distribution, and reproduction in any medium, provided the original work is properly cited (http://creativecommons.org/licenses/by/4.0/deed.en).

Received: 02.07.2020

Accepted: 13.08.2020; Published: 25.02.2021 